\title{
EMPODERAMENTO FEMININO: uma análise a partir da teoria do poder simbólico de Pierre Bourdieu
}

\author{
Robison Tramontina ${ }^{1}$ \\ Gabriele Ana Paula Danielli Schmitz ${ }^{2}$
}

\begin{abstract}
RESUMO
O presente trabalho trata sobre o empoderamento feminino sob a perspectiva da teoria do poder simbólico de Pierre Bourdieu. A escolha do tema motiva-se pela sua contemporaneidade e pela recorrente discussão em torno do empoderamento feminino. A questão que orienta esta investigação é a seguinte: é possível sustentar a ideia de que o empoderamento feminino é uma forma de poder simbólico? Para responder a esta indagação o desdobramento argumentativo teve como base a seguinte trajetória: primeiro abordou-se o significado de empoderamento feminino; na sequência se fez uma abordagem acerca da teoria do poder simbólico de Pierre Bourdieu; por último analisou-se a possibilidade de considerar o empoderamento feminino uma forma de poder simbólico. O método de pesquisa adotado foi o método dedutivo e como metodologia a pesquisa bibliográfica.
\end{abstract}

Palavras-chave: Empoderamento. Poder Simbólico.

\section{FEMININE EMPOWERMENT: AN ANALYSIS FROM THE THEORY OF SYMBOLIC POWER OF PIERRE BOURDIEU}

\begin{abstract}
This paper deals with female empowerment from a perspective of Pierre Bourdieu's theory of symbolic power. The choice of the theme is motivated by its contemporaneity and by using a discussion about female empowerment. The question guiding this research is this: Is it possible to sustain an idea that female empowerment is a form of symbolic power? To respond to this statement of argumentative unfolding was based on the following trajectory: first addressed the meaning of female empowerment; An approach was then taken on the theory of symbolic power of Pierre Bourdieu; Finally, the possibility of considering female empowerment as a form of symbolic power was analyzed. The method of research adopted for the deductive method and as methodology the bibliographic research.
\end{abstract}

Keywords: Empowerment. Symbolic power.

\footnotetext{
${ }^{1}$ Professor de Filosofia do Direito, Argumentação Jurídica e Teorias da Justiça. Doutor em Filosofia pela Pontifícia Universidade Católica do Rio Grande do Sul - PUCRS ( CAPES 6). Professor do Programa de Mestrado em Direitos Fundamentais da Universidade do Oeste de Santa Catarina - UNOESC (CAPES 3). Editor Assistente da Espaço Jurídico Journal of Law [EJJL] (Qualis A1, CAPES, ISSN 2179-7943). Sócio-efetivo da Associação Brasileira de Editores Científicos - ABEC. Revisor de diversos periódicos.

${ }^{2}$ Mestre em Direito pela Universidade do Oeste de Santa Catarina - UNOESC; Pós-Graduada em Direito Aquaviário e Atividade Portuária pela Univali e em Direito do Estado pela Universidade Anhanguera; Graduada em Direito pela Universidade do Sul de Santa Catarina - UNISUL(2008); Advogada Efetiva da Prefeitura Municipal de Pinhalzinho, Estado de Santa Catarina; Coordenadora do Curso de Direito da Universidade do Oeste de Santa Catarina - UNOESC - Campus Aproximado de Pinhalzinho;
} 


\section{INTRODUÇÃO}

O empoderamento feminino é um tema que se caracteriza pela sua contemporaneidade, especialmente, quando abordado sob o viés da discriminação de gênero, visto que a, princípio, homens e mulheres devem ter garantidos os mesmos direitos.

Nesse sentido, o problema que propõe à análise é verificar se é possível sustentar a ideia de que o empoderamento feminino é uma forma de poder simbólico, a partir da teoria do poder simbólico de Pierre Bourdieu.

Para tanto, inicialmente será apresentado o conceito de empoderamento feminino, com ênfase nas divergências entre a visão institucionalizada e a feminista, a fim de garantir um maior aprofundamento no tema.

Na sequência, será apresentada a teoria do poder simbólico de Pierre Bourdieu, no intuito de possibilitar a compreensão da ideia desenvolvida pelo autor, para que, ao final, seja possível responder a pergunta que orienta essa pesquisa, qual seja: se o empoderamento feminino pode ser considerado uma forma de poder simbólico.

O estudo ora apresentado, tem caráter teórico e se desenvolveu com base no método lógico de abordagem dedutiva do tema, utilizou-se a pesquisa bibliográfica por meio da leitura e interpretação de textos publicados em diversos meios.

\section{O EMPODERAMENTO DA MULHER}

Antes de se adentrar ao estudo do empoderamento da mulher, uma observação, que é de extrema importância, não pode deixar de ser feita: ainda não há um consenso acerca de seu significado, trata-se de um termo polissêmico.

Existem, pelo menos, duas vertentes totalmente antagônicas acerca do que é o empoderamento da mulher: uma institucionalizada, utilizada pela Organização das Unidas (ONU) e pelos órgãos governamentais, que liga o empoderamento à questão econômica; e outra feminista, que está ligada a todo o processo de conquista da autodeterminação das mulheres, através de sua libertação das amarras do patriarcado. (SARDENBERG, 2009, p. 2)

Para facilitar a compreensão dos diferentes significados da expressão empoderamento das mulheres, primeiro será feita uma análise do seu sentido institucionalizado, a partir do entendimento defendido pela ONU e, posteriormente, do seu viés feminista.

A ONU criou, em junho de 2010, a ONU Mulheres, cujo objetivo principal é promover a igualdade de gênero e o empoderamento das mulheres.

Após a criação da ONU Mulheres, houve uma disseminação do uso do termo empoderamento, no entanto, muitas vezes ele é empregado nas discussões públicas, sem que se tenha clareza acerca do seu real significado no contexto em que está sendo tratado.

Então, no intuito de esclarecer qual o sentido da palavra empoderamento, quando empregada no contexto das discussões travadas pela ONU em torno dos direitos 
das mulheres, nada mais lógico do que buscar informações junto à própria ONU Mulheres.

Na cartilha denominada "Princípios do Empoderamento das Mulheres", editada pela ONU, no ano de 2016, é possível encontrar qual é o sentido institucionalizado dessa expressão.

Na página oficial da ONU Mulheres é possível encontrar a cartilha, acima referida, que explica, detalhadamente, qual a visão institucionalizada do empoderamento das mulheres.

Nessa cartilha, a ONU esclarece que o termo empoderamento, expressa a importância da promoção da participação das mulheres no âmbito dos negócios, implementando, assim, a economia mundial. (ONU, 2016, p. 4)

Ou seja, em que pese muito se fale acerca do empoderamento, essa palavra foi utilizada pela ONU com um sentido muito particular, que é implementar, tanto no campo público, quanto no privado, medidas que encorajem as mulheres a atuar no mundo dos negócios.

Para tanto, a ONU desenvolveu sete princípios norteadores do empoderamento das mulheres e são eles: (ONU, 2016, p. 3)

1. "estabelecer liderança corporativa de alto nível para a igualdade de gênero";

2. "tratar todos os homens e mulheres de forma justa no trabalho - respeitar e apoiar os direitos humanos e a não discriminação";

3. "garantir a saúde, a segurança e o bem estar de todos os trabalhadores e as trabalhadoras";

4. "promover a educação, a formação e o desenvolvimento profissional das mulheres";

5. "implementar o desenvolvimento empresarial e as práticas da cadeia de suprimentos e de marketing que empoderem as mulheres";

6. "promover a igualdade através de iniciativas e defesa comunitária;

7. "mediar e publicar os progressos para alcançar a igualdade de gênero".

Ou seja, o termo empoderamento, tal como implementado pela ONU Mulheres, tem um sentido muito específico, que é implementar a igualdade de gênero nas relações de trabalho e empreendimento.

Mas, uma dúvida que emerge, é acerca de quais motivos impulsionaram a ONU Mulheres a tomar essa iniciativa de implementar e difundir a ideia de empoderamento feminino.

$\mathrm{Na}$ busca de possíveis respostas a essa questão encontrou-se um estudo publicado em 2015 pelo Mckinsey Global Institute, que aponta o impacto financeiro decorrente da inserção das mulheres no mercado de trabalho.

Segundo levantamentos da Mckinsey Global Institute (2015, p. 2), com a introdução das mulheres no mercado de trabalho, principalmente empreendendo e ocupando cargos de liderança, haveria a injeção de algo entre 410 a 850 bilhões de reais ao produto interno bruto (PIB) do Brasil até o ano de 2025 (somando o sul e o nordeste), valor este extremamente significativo para a economia.

Em 2015, apesar de a força de trabalho feminino corresponder a $62 \%$ do total, apenas $35 \%$ do PIB é oriundo do trabalho feminino e, isso se deve, a diversos fatores, dentre eles a diferença salarial percebida por homens e mulheres pelo mesmo trabalho, já que a mão de obra feminina é menos valorizada que a masculina. (MCKINSEY GLOBAL INSTITUTE (2015, p. 3-4). 
Há, portanto, um interesse econômico que alavancou essa ideia de promover o empoderamento das mulheres, pois, percebeu-se que a sua inserção no mercado de trabalho, traria benefícios para a economia, como um todo.

Essa apropriação do termo empoderamento pelos órgãos governamentais e pela ONU gera certo desconforto para as feministas, já que sua compreensão acerca de seu significado é totalmente oposta.

Segundo Sardenberg $(2009$, p. 2), na vertente feminista, o empoderamento está relacionado a todo o processo de libertação das mulheres. Isso significa dizer que empoderamento é quando as mulheres conseguem se libertar do poder patriarcal e tem a possibilidade de se autodeterminar, no sentido de colocar um basta à opressão de gênero.

O empoderamento é considerado um processo, pois está em constante transformação, cujo início ocorre com a conscientização das mulheres sobre a opressão masculina, a fim que possam exigir que a sociedade passe a entender a necessidade de mudanças que garantam a diminuição da desigualdade de gênero. (SARDENBERG, 2009, p. 8)

Enfim, essa ideia de empoderamento das mulheres, tal como desenvolvida pela ONU, busca, a princípio, alertar a sociedade para a necessidade da adoção de medidas tendentes a reduzir a discriminação de gênero, principalmente no plano econômico, para que, no futuro, homens e mulheres possam efetivamente desfrutar dos mesmos direitos, enquanto que o empoderamento defendido pelas feministas, consiste no processo de libertação e, consequente, autodeterminação das mulheres.

\section{A TEORIA DO PODER SIMBÓLICO}

Pierre Félix Bourdieu foi um sociólogo francês, dentre os mais importantes de sua época, que viveu entre os anos de 1930 e 2002 e dedicou parte de sua vida ao estudo dos problemas sociais, especialmente aqueles ligados a questão cultural. (EBIOGRAFIA, 2015, s.p.)

Na obra denominada "O poder simbólico" Bourdieu (1989) desenvolve sua teoria acerca de como o poder é legitimado pelas pessoas sem que percebam a violência simbólica que sofrem.

A primeira abordagem de Bourdieu (1989, p. 6) remete à construção dos "sistemas simbólicos", que são as estruturas que dão sustentação ao poder simbólico.

Segundo o autor, é por meio dos símbolos estabelecidos pela classe dominante, tais como a língua, arte e ciência, que se formam as estruturas de comunicação e conhecimento, que vão resultar na integração social e, portanto, no consenso em relação às subjetividades. (BOURDIEU, 1989, p. 8)

O uso da língua, para comunicação, demonstra de maneira muito clara a forma como os símbolos levam ao consenso social, sobretudo pelo fato de que é através do som emitido pelas palavras que se constrói seu sentido, que é compreendido e aceito por todos, configurando, assim, uma estrutura estruturada. (BOURDIEU, 1989, p. 9)

Assim, no mundo social, é por meio do conhecimento e da comunicação, que os símbolos estabelecem o consenso, pois todos passam a concordar com seus significados e, assim, legitimam o poder simbólico de uma classe sobre a outra, a exemplo do que acontece com a divisão de classes de Marx. (BOURDIEU, 1989, p. 10) 
É possível afirmar, enfim, que as estruturas decorrentes dos sistemas simbólicos exercem um poder estruturado, posto que seu sentido é imediatamente compreendido e aceito. (BOURDIEU, 1989, p. 9)

A ideia central da tese do poder simbólico consiste na compreensão de que existe um poder invisível, o qual, para ser exercido, depende, essencialmente, da ignorância daqueles que a ele são submetidos e dos que o praticam. (BOURDIEU, 1989, p. 8-9)

O sentido em que Bourdieu (1989, p. 8-9) emprega o termo ignorância é de que os atores não se deem conta de que a visão de mundo, com a qual eles concordam e aceitam, decorre de uma imposição forçosa advinda das classes dominantes, com a intenção de manter sua hegemonia sobre os dominados.

No campo cultural, o poder simbólico é exercido pela cultura dominante, que cria uma ideologia, aparentemente universal, quando, na verdade serve para classificar as sub-culturas que irão se definir a partir da sua posição em relação à cultura dominante. . (BOURDIEU, 1989, p. 10-11)

No caso da imposição cultural, o poder simbólico exerce, na verdade, uma função política, pois desempenha o papel de legitimar a dominação de uma classe sobre as demais, garantindo sua hegemonia. (BOURDIEU, 1989, p. 10-11)

Esse poder simbólico somente se confirma se for compreendido como algo não arbitrário, já que a sua principal característica é impor uma visão de mundo dominante, sem que os dominados percebam sua arbitrariedade. A partir do momento em que se toma consciência da arbitrariedade, o poder simbólico deixa de existir. (BOURDIEU, 1989, p. 14-15)

Mas, o que faz com que as pessoas aceitem esse poder arbitrário, sem ao menos se dar conta da violência que está mascarada por detrás dele? Bourdieu (1989, p. 15) traz a resposta a esta questão: “[...] é a crença na legitimidade das palavras e daquele que as pronuncia, crença, cuja produção não é das palavras."

O poder simbólico faz com que as pessoas concordem com as atitudes dominadoras, compreendendo-as como naturais, ou seja, há aceitação da condição de inferior.

O poder simbólico, enfim, se mantém em virtude da crença na sua legitimidade e mais, ele não está estagnado, pelo contrário, está em constante construção, isso porque, a classe dominante, sempre estará buscando novas formas para exercer seu poder sobre os dominados, de forma que eles o legitimem sem que seja necessário o emprego da violência aparente.

\section{O EMPODERAMENTO FEMININO SOB A PERSPECTIVA DA TEORIA DO PODER SIMBÓLICO}

No caso específico da hierarquia masculina, é fácil perceber que essa hegemonia dos homens prescinde se justificação, dispensa discursos legitimadores, até mesmo porque não existem razões claras e específicas que justifiquem os motivos pelos quais o sexo masculino goza de uma posição hierárquica em relação ao feminino. (BOURDIEU, 2016, p. 22)

Não se pode negar, todavia, que as diferenças biológicas tem um papel extremamente relevante na hierarquia do sexo masculino, pois a virilidade do homem, por si só, já é empregada como um sinal de sua superioridade sobre a mulher. Até 
mesmo a gestação é compreendida como um êxito masculino, quando se emprega o argumento de que a mulher depende da potência do homem para torná-la fecunda (BOURDIEU, 2016, p. 25-26)

Assim, com base nesse discurso de superioridade do homem, historicamente, houve a construção da noção de inferioridade da mulher, baseada na sua perspectiva biológica, haja vista que os naturalistas buscavam descrever as fêmeas como seres frágeis, que deveriam se manter na castidade, pois era isso que eles esperavam de suas mulheres e filhas. (BOURDIEU, 2016, p. 30)

O corpo da mulher foi culturalmente incentivado a se manter fechado, e protegido como algo sagrado. Nessa vertente é possível perceber que às mulheres se impõe a necessidade de cruzar as pernas, usar roupas que cubram seu corpo, protegendo-o de olhares. Enfim, são todas medidas que impõe a necessidade de proteção, dada a sua inferioridade. (BOURDIEU, 2016, p. 31-32)

Em decorrência dessa dominação masculina, as mulheres, há muito tempo, buscam afirmar sua identidade na sociedade, em que pese essa busca pelo reconhecimento da identidade não possuir começo meio e fim, pois se trata de uma tarefa infinita, que sempre está em desenvolvimento e, tampouco, é uma luta exclusiva das mulheres, mas sim de todas as classes contingenciadas. (BAUMAN, 2005, p. 16)

No entanto, dadas as inúmeras influências a que as pessoas são submetidas na sociedade globalizada, manter uma identidade se torna uma tarefa árdua, especialmente porque não há como uma pessoa não ser afetada por princípios, modos, ideias de outras identidades com as quais têm contato. (BAUMAN, 2005, p. 20-21)

Nesse sentido, é possível perceber que, até mesmo os movimentos feministas, foram afetados por essa multiplicidade de ideias e influências oriundas da globalização, pois as mulheres não estão mais direcionadas à conquista de um direito especifico, como fizeram no passado quando, lutavam pelo direito ao voto e ao trabalho remunerado, por exemplo. Hoje a busca é pela igualdade de gênero em todos os sentidos, seja no campo financeiro, social ou sexual.

$\mathrm{Na}$ década de 80, segundo Bauman (2005, p. 41-47), as minorias estigmatizadas ganharam um espaço jamais visto, trazendo à tona as discussões em torno do reconhecimento, no entanto, todos os grupos que buscavam reconhecimento tinham um ponto em comum, evitam falar na questão econômica, no dinheiro, que é um dos principais fatores que contribui para a acentuação das desigualdades.

Entretanto, não basta a luta para combater a desigualdade, quando o poder econômico define aqueles que terão reconhecimento e aqueles que serão considerados uma subclasse humana, por não se encaixarem no padrão estabelecido pelos detentores do poder ou, melhor, por não renderem, financeiramente, aquilo que se espera.

Bauman (2005, p. 47) faz uma dura crítica ao sistema capitalista, quando menciona a produção do "lixo humano", que se trata, na prática, do descarte de pessoas que não servem para o capitalismo, ou seja, são pessoas praticamente invisíveis aos olhos da sociedade, haja vista que não são capazes de gerar lucro. Nesse caso, não há apenas falta de reconhecimento, mas sim exclusão social.

As mulheres, enquanto não conseguiram mostrar sua importância para o mundo capitalista, ficaram à mercê do reconhecimento social, foram excluídas, fazendo uso do conceito de exclusão de Bauman (2005) e isso, segundo Beauvoir (1970, p. 97) se justifica, inicialmente, pela fragilidade do corpo feminino, já que parte do triunfo do patriarcado se deve ao privilégio biológico que permitiu aos homens afirmarem-se sozinhos como sujeitos soberanos. 
Esse privilégio biológico conferido aos homens se deve muito ao fato de que, em virtude da maternidade, as mulheres ficam improdutivas por um determinado período, principalmente durante a gestação e a fase e, que ficam dedicadas aos cuidados com o bebê gerado. A gestação torna as mulheres menos atrativas para as empresas, que acabam preferindo os trabalhadores do sexo masculino, que serão produtivos ao longo de grande parte de sua vida, ao menos que venham a ser acometidos de uma doença que lhes afaste do trabalho.

Em que pese, inicialmente, os postos de trabalho ter sido ocupados, majoritariamente, pelos homens, durante o período da segunda guerra mundial, as empresas foram obrigadas a buscar nas mulheres a mão de obra trabalhadora, o que só aconteceu porque elas tiveram que assumir o papel dos homens nas fábricas, para que eles pudessem ir aos campos de batalha. (SOUZA, 2015, s. p.)

Inclusive, há um fato curioso relacionado à famosa imagem da mulher trabalhadora, usando um lenço na cabeça, vestindo uma camisa jeans com as mangas arregaçadas, mostrando seu bíceps definido e com a inscrição em inglês "we can do it".

Em que pese essa imagem seja propagada pelas feministas, como um símbolo da sua luta, ela, originalmente, foi criada em 1943, por J. Howard Miller para a empresa americana Westinghouse Electric Corporation, para atrair as mulheres a ocupar as vagas de trabalho que estavam abertas, em função da grande demanda oriunda dos trabalhadores chamados a combater durante a segunda guerra mundial. Ou seja, o sentido dessa propaganda era fazer com que as mulheres ocupassem as vagas deixadas pelos homens que haviam partido para lutar na guerra, o que, de fato ocorreu, no entanto, por salários bem inferiores aos pagos aos homens.

É na esteira da busca pelo reconhecimento da identidade das mulheres, principalmente, levando em consideração a questão econômica, pois as mulheres ainda têm uma condição financeira inferior aos homens, que surge o empoderamento da mulher, na sua vertente institucionalizada.

Após verificar quais foram os motivos pelos quais a mulher ingressou no mercado de trabalho, uma pergunta que se torna inevitável é saber por qual razão a ONU e os órgãos públicos dão tanta ênfase à questão do empoderamento da mulher.

$\mathrm{Na}$ cartilha da ONU (2016, p. 16), é possível encontrar alguns indícios que conduzem à uma relação com a teoria do poder simbólico de Pierre Bourdieu.

Quando são descritos, uma a um, os princípios do empoderamento da mulher, a ONU (2016, p. 16) menciona que um dos objetivos com o empoderamento das mulheres, é a aceleração do desenvolvimento econômico, uma vez que as mulheres reinvestem mais seu dinheiro, em comparação com os homens o que, consequentemente, faz com que a economia esteja sempre aquecida, através do consumo.

Enfim, quanto mais dinheiro a mulher ganhar, mais ela irá consumir, isso porque ainda são as mulheres as maiores responsáveis pelo consumo das famílias, em virtude de que acumulam a função de profissional com os cuidados com o lar.

Além disso, as estratégias de marketing, cada vez mais, são voltadas ao público feminino, justamente visando atingir as mulheres da chamada "Geração Y", que são mulheres que vivem conectadas à internet e ao telefone celular, que gostam de ter acesso rápido àquilo que procuram e que, além de gerenciar seus lares, também trabalham fora e, portanto, são potenciais consumidoras, pois tem uma renda própria. (JOHNSON, LEARNED, 2012, p. 120-122).

Essa migração das mulheres para a internet fez com que as empresas passassem a desenvolver mecanismos para criar perfis de consumidoras, verificando quais são os 
sites que elas mais visitam, quais ferramentas elas usam, encaminhando testes e pesquisas on-line, entre outros. (JOHNSON, LEARNED, 2012, p. 232-233)

Ocorre que, para que as mulheres, de fato passem a consumir mais, elas devem se sentir aptas a isso, e é justamente nesse ponto que entra a reflexão aqui proposta.

Em primeiro lugar, cabe ressaltar que a expressão empoderamento, da forma como foi institucionalizada, leva a equívoca sensação de que as mulheres são poderosas, podem fazer tudo aquilo que desejam, quando, na verdade, é sabido que a sociedade ainda não trata a mulher como um ser poderoso, longe disso. As mulheres são encorajadas a trabalhar, a assumir as mais diversas funções, no entanto, ainda são muito cobradas em relação as atividades domésticas, ao pudor que devem ter nas suas atitudes, agindo da forma que se espera socialmente, o que acaba gerando sérios danos, inclusive de ordem psicológica, pois passam a viver num grande conflito entre a vida pessoal e profissional.

Nesse sentido, Fredrickson; Roberts (1997) descrevem algumas das consequências psicológicas enfrentadas pelas mulheres em virtude das cobranças sociais para que elas se encaixem nos padrões socialmente impostos, e são elas: vergonha, ansiedade, culpa, alterações de humor.

Empoderar as mulheres para que elas se tornem empreendedoras e líderes no mercado profissional pode ser mais uma face da violência simbólica, pois o objetivo maior dessa buscar é aumentar o PIB dos países, incrementando, assim, a economia, a exemplo do Brasil que, com a estratégia do empoderamento das mulheres poderá aumentar em até 850 bilhões de reais seu PIB.

Num país ocidental, cujo capitalismo é dominante, como é o caso do Brasil, o poder simbólico consiste, justamente, na imposição dessa cultura dominante, que conduz as mulheres a essa ideia de empoderamento que, nada mais é do que uma ideologia utilizada para legitimar a dominação, pois foi somente após a sociedade ter se dado conta de que as mulheres poderiam sim dar lucros, que elas foram inseridas no mercado de trabalho. Antes disso, as mulheres eram totalmente excluídas e relegadas aos afazeres domésticos que não são remunerados, tampouco tem jornada de trabalho estipulada. (BOURDIEU, 1989, p. 10-11)

Seguindo a ideia de Bourdieu (1989), de que o poder simbólico se confirma quando aceito como não arbitrário, ou seja, quando os dominados ignoram sua arbitrariedade, é possível desconfiar que todo esse marketing em torno do empoderamento das mulheres esteja maquiando uma violência simbólica.

\section{CONSIDERAÇÕES FINAIS}

O empoderamento feminino, conforme mencionado no início deste trabalho, é um tema que está na pauta das dissuasões entorno da igualdade de gênero, motivo este que impulsionou esta pesquisa.

Para responder ao problema proposto, verificar se é possível sustentar a ideia de que o empoderamento feminino é uma forma de poder simbólico, utilizou-se como base a teoria do poder simbólico de Pierre Bourdieu.

Verificou-se que existe o empoderamento da mulher institucionalizado pela Organização das Unidas (ONU) e pelos órgãos governamentais, que liga o empoderamento à questão econômica e outra feminista, que está ligada a todo o 
processo de conquista da autodeterminação das mulheres, decorrente da sua luta contra o patriarcado.

Em seguida, foi apresentada a teoria do poder simbólico de Pierre Bourdieu, que consiste na compreensão de que existe um poder invisível, que, para ser exercido, depende da ignorância daqueles que a ele são submetidos e dos que o praticam.

A partir da compreensão da ideia do poder simbólico, fez-se um contraponto com o empoderamento feminino, que permitiu concluir que o empoderamento feminino institucionalizado, que impõe à mulher a tomada do seu lugar no mercado, como um ser gerador de lucros para o capitalismo, pode ser considerado poder simbólico, desde que aceito como não arbitrário.

O estudo ora apresentado se desenvolveu com base no método lógico de abordagem dedutiva do tema, utilizou-se a pesquisa bibliográfica por meio da leitura e interpretação de textos publicados em diversos meios.

\section{REFERÊNCIAS}

BAUMAN, Zygmunt. Identidade. Trad. Carlos Alberto Medeiros. Rio de Janeiro: Zahar, 2005.

BEAUVOIR, Simone de. O segundo sexo: fatos e mitos. 2 ed. Trad. Sérgio Milliet. Difusão Européia do Livro: São Paulo,1970.

BOURDIEU, Pierre. A dominação masculina: a condição feminina e a violência simbólica. Trad. Maria Helena Kuhner. 3 ed. Rio de Janeiro: Bestbolso, 2016.

BOURDIEU, Pierre. O poder simbólico. Trad. Fernando Tomaz. Berrando Brasil S. A: Rio de Janeiro, 1989.

E-BIOGRAFIA. Pierre Bourdieu, 2015. Disponível em: <https://www.ebiografia.com/pierre_bourdieu/>. Acesso em: 10 de janeiro de 2017.

FREDRICKSON, Barbara L; ROBERTS, Tommi Ann. Objetification theory: toward understanding women's lived experiences and mental health risks. 1997. Disponivel em: <http://www.sanchezlab.com/pdfs/FredricksonRoberts.pdf>. Acesso em: 05 de junho de 2016.

JOHNSON, Lisa e LEARNED, Andrea. Por que as mulheres compram? Estratégias de marketing para conquistar o público feminino. 2. Ed. São Paulo: Ed. Saraiva, 2012.

ORGANIZAÇÃO DAS NAÇÕES UNIDAS. Os princípios do empoderamento das mulheres, 2016. Disponível em: < http://www.onumulheres.org.br/wpcontent/uploads/2016/04/cartilha_WEPs_2016.pdf>. Acesso em 09 de janeiro de 2017.

MCKINSEY GLOBAL INSTITUTE. O poder da igualdade: como o avanço da igualdade das mulheres pode acrescentar us $\$ 12$ trilhões ao crescimento global, 2015. Disponível em: <file:///C:/Users/gabri/Downloads/DOC_PARTICIPANTE_EVT_2990_144959867109 6_K-Comissao-Mista-CMCVM- 
20151208REU016_parte5750_RESULTADO_1449598671096.pdf>. Acesso em: 09 de janeiro de 2017.

SARDENBERG, Cecília. Conceituando "Empoderamento" na Perspectiva Feminista (transcrição revisada da comunicação oral apresentada ao I Seminário Internacional: Trilhas do Empoderamento de Mulheres - Projeto TEMPO, NEIM/UFBA, Salvador, 2006, ampliado na versão 2009. Disponível em: < https://repositorio.ufba.br/ri/handle/ri/6848 > . Acesso em: 26 de janeiro de 2017.

SOUZA, Lisandra. "We Can Do It!": você conhece a origem de um dos grandes símbolos do movimento feminista? Disponível em: $<$ http://diariosdeumafeminista.blogspot.com.br/2015/11/we-can-do-it-voce-conheceorigem-de-um_22.html>. Acesso em 10 de janeiro de 2017. 